\title{
Esophageal stenting for benign and malignant disease: European Society of Gastrointestinal Endoscopy (ESGE) Clinical Guideline
}

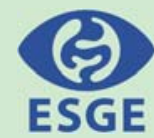

Authors

Institutions
Manon C. W. Spaander ${ }^{1}$, Todd H. Baron ${ }^{2}$, Peter D. Siersema ${ }^{3}$, Lorenzo Fuccio ${ }^{4}$, Brigitte Schumacher ${ }^{5}$, Àngels Escorsell ${ }^{6}$, Juan-Carlos Garcia-Pagán ${ }^{6}$, Jean-Marc Dumonceau ${ }^{7}$, Massimo Conio ${ }^{8}$, Antonella de Ceglie ${ }^{9}$, Janusz Skowronek ${ }^{10}$, Marianne Nordsmark ${ }^{11}$, Thomas Seufferlein ${ }^{12}$, André Van Gossum ${ }^{13}$, Cesare Hassan ${ }^{14}$, Alessandro Repici ${ }^{15}$, Marco J. Bruno ${ }^{1}$

Institutions are listed at end of article.
Bibliography

DOI http://dx.doi.org/

$10.1055 / \mathrm{s}-0042-114210$

Published online: 14.9.2016

Endoscopy 2016; 48: 939-948

(c) Georg Thieme Verlag KG

Stuttgart · New York

ISSN 0013-726X

Corresponding author

M.C.W. Spaander, MD PhD

Department of

Gastroenterology and

Hepatology

Room Hs-308

Erasmus Medical Centre

Rotterdam

PO Box 2040

3000 CA Rotterdam

3015 CE Rotterdam

The Netherlands

Fax: +31-10-7035172

v.spaander@erasmusmc.nl
This Guideline is an official statement of the European Society of Gastrointestinal Endoscopy (ESGE), endorsed by the European Society for Radiotherapy and Oncology (ESTRO), the European Society of Digestive Endoscopy (ESDO), and the European Society for Clinical Nutrition and Metabolism (ESPEN). The Grading of Recommendations Assessment, Development, and Evaluation (GRADE) system was adopted to define the strength of recommendations and the quality of evidence.

Main recommendations for malignant disease

1 ESGE recommends placement of partially or fully covered self-expandable metal stents (SEMSs) for palliative treatment of malignant dysphagia over laser therapy, photodynamic therapy, and esophageal bypass (strong recommendation, high quality evidence).

2 For patients with longer life expectancy, ESGE recommends brachytherapy as a valid alternative or in addition to stenting in esophageal cancer patients with malignant dysphagia. Brachytherapy may provide a survival advantage and possibly a better quality of life compared to SEMS placement alone. (Strong recommendation, high quality evidence.)

3 ESGE recommends esophageal SEMS placement as the preferred treatment for sealing malignant tracheoesophageal or bronchoesophageal fistula (strong recommendation, low quality evidence). 4 ESGE does not recommend the use of concurrent external radiotherapy and esophageal stent treatment. SEMS placement is also not recommended as a bridge to surgery or prior to preoperative chemoradiotherapy. It is associated with a high incidence of adverse events and alternative satisfactory options such as placement of a feeding tube are available. (Strong recommendation, low quality evidence.)

Main recommendations for benign disease

1 ESGE recommends against the use of self-expandable stents (SEMSs) as first-line therapy for the management of benign esophageal strictures because of the potential for adverse events, the availability of alternative therapies, and costs (strong recommendation, low quality evidence). 2 ESGE suggests consideration of temporary placement of SEMSs as therapy for refractory benign esophageal strictures (weak recommendation, moderate evidence).

Stents should usually be removed at a maximum of 3 months (strong recommendation, weak quality evidence).

3 ESGE suggests that fully covered SEMSs be preferred over partially covered SEMSs for the treatment of refractory benign esophageal strictures, because of their lack of embedment and ease of removability (weak recommendation, low quality evidence).

4 For the removal of partially covered esophageal SEMSs that are embedded, ESGE recommends the stent-in-stent technique (strong recommendation, low quality evidence).

5 ESGE recommends that temporary stent placement can be considered for treating esophageal leaks, fistulas, and perforations. The optimal stenting duration remains unclear and should be individualized. (Strong recommendation, low quality evidence.)

6 ESGE recommends placement of a SEMS for the treatment of esophageal variceal bleeding refractory to medical, endoscopic, and/or radiological therapy, or as initial therapy for patients with massive esophageal variceal bleeding (strong recommendation, moderate quality evidence). 


$\begin{array}{ll}\text { Abbreviations } \\ \text { BMI } & \text { body mass index } \\ \text { CI } & \text { confidence interval } \\ \text { CSEMS } & \text { covered self-expandable metal stent } \\ \text { ESDO } & \text { European Society of Digestive Oncology } \\ \text { ESGE } & \text { European Society of Gastrointestinal Endoscopy } \\ \text { ESPEN } & \text { European Society for Clinical Nutrition and Metabolism } \\ \text { ESTRO } & \text { European Society for Radiotherapy and Oncology } \\ \text { FCSEMS } & \text { fully covered self-expandable metal stent } \\ \text { GEJ } & \text { gastroesophageal junction } \\ \text { GRADE } & \text { Grading of Recommendations Assessment, } \\ & \text { Development and Evaluation } \\ \text { HR } & \text { hazard ratio } \\ \text { PCSEMS } & \text { partially covered self-expandable metal stent } \\ \text { PEG } & \text { percutaneous endoscopic gastrostomy } \\ \text { PDT } & \text { photodynamic therapy } \\ \text { RBES } & \text { refractory benign esophgeal stricture } \\ \text { RR } & \text { risk ratio or relative risk } \\ \text { RCT } & \text { randomized controlled trial } \\ \text { RTCT } & \text { radiotherapy combined with chemotherapy } \\ \text { SEMS } & \text { self-expandable metal stent } \\ \text { SEPS } & \text { self-expandable plastic stent } \\ \text { TIPS } & \text { transjugular intrahepatic portosystemic shunt } \\ \text { QoL } & \text { quality of life } \\ & \end{array}$

\section{Introduction}

$\nabla$

Esophageal cancer is the eighth most common cancer worldwide with an estimated 456000 new cases and 400000 deaths in 2012 [1]. More than $50 \%$ of patients with esophageal carcinoma have metastatic disease at the time of diagnosis. Dysphagia is the most common symptom of incurable obstructive esophageal cancer and can be treated by esophageal stent placement. In recent years different designs of esophageal stents have emerged for improving dysphagia and quality of life in patients with malignant esophageal tumor, malignant fistula, or extrinsic compression $[2,3]$. Esophageal stent placement in patients with incurable esophageal cancer is aimed at maintaining oral intake and improving quality of life, but it carries a risk of adverse events such as hemorrhage, pain, and fistula [4]. The current variety of commercially available stents for malignant disease comprises uncovered self-expandable metal stents (SEMSs); fully covered self-expandable metal stents (FCSEMSs), in which the entire length of the stent is covered; partially covered self-expandable metal stents (PCSEMSs), in which the proximal and distal ends of the stent are devoid of a covering; and fully covered self-expandable plastic stents (SEPSs). All currently available SEMSs are made of nitinol, a nickel and titanium alloy. In Europe, the types of stents that are predominately used in the treatment of malignant dysphagia are PCSEMSs and FCSEMSs.

Esophageal stents are also commonly used for the treatment of benign esophageal diseases, albeit most stents are not officially approved for this indication. Common and investigative indications include treatment of refractory benign esophageal stricture (RBES), sealing of perforations, leaks, and treatment of acute esophageal variceal bleeding. FCSEMS and PCSEMS as well as SEPS are used for this indication, but only the latter has formal approval for RBES.All stents used for benign esophageal conditions should be removed, except for the self-expandable biodegradable stents that have recently become available in Europe.
This clinical Guideline aims to describe the role of esophageal stents in patients with malignant or benign esophageal disease and makes recommendations on circumstances that warrant their use.

\section{Methods \\ $\checkmark$}

The European Society of Gastrointestinal Endoscopy (ESGE) commissioned this Guideline and appointed a Guideline leader (M.J.B.) who invited the listed authors. The key questions were prepared by the coordinating team (M.C.W.S., J.-M.D., C.H., M.J. B.) and then approved by the other members (see Appendix e1, available online). The coordinating team established task force subgroups, each with a leader (P.D.S.for malignant disease and T.H.B. for benign disease), and divided the key topics among these task forces.

Each task force performed a systematic literature search to prepare evidence-based and well-balanced statements on their assigned key questions. All selected articles were graded for the level of evidence and strength of recommendation according to the Grading of Recommendations Assessment, Development and Evaluation (GRADE) system [5]. The numbers of articles retrieved and selected by each task force are indicated in the evidence tables (see Tables e1 - e6 in Appendix e2, available online).

Each task force proposed statements for their assigned key questions, which were discussed during a meeting in Amsterdam (April 2015). In August 2015, a draft prepared by the coordinating team was sent to all group members. It was also sent for review and endorsement to the European Society for Radiotherapy and Oncology (ESTRO), the European Society of Digestive Oncology (ESDO), and the European Society for Clinical Nutrition and Metabolism (ESPEN). The manuscript was reviewed by two members of the ESGE Governing Board and sent for further comments to the National Societies and ESGE Individual Members. After agreement on a final version, the manuscript was submitted to Endoscopy for publication, All authors agreed on the final revised manuscript.

This Guideline was issued in 2016 and will be considered for review and update in 2021 or sooner if new and relevant evidence becomes available. Any updates to the Guideline in the interim will be noted on the ESGE website: http://www.esge.com/esgeguidelines.html.

\section{Recommendations and statements} $\nabla$

\section{ESOPHAGEAL STENTS IN MALIGNANT DISEASE}

ESGE recommends placement of partially or fully covered self-expanding metal stents (SEMSs) for palliation of malignant dysphagia over laser therapy, photodynamic therapy, and esophageal bypass (strong recommendation, high quality evidence).

ESGE recommends against the placement of nonexpandable and expandable plastic stents for the palliation of malignant esophageal strictures (strong recommendation, high quality evidence).

\section{Efficacy}

Photodynamic therapy (PDT), laser therapy, and esophageal bypass have not been shown to be superior to SEMS placement for the palliation of malignant dysphagia in several randomized con- 
trolled trials (RCTs) [6-11]. From 1993 up to 2005 several RCTs have compared SEMS versus rigid plastic stents [12-18]. One of the largest published RCTs including 217 patients [17] showed a better improvement in dysphagia score at 1 and 6 weeks with SEMS compared to rigid plastic stents and fewer late adverse events. Systematic reviews and meta-analyses showed that SEMS insertion was superior to rigid plastic stents in terms of improvement and recurrence of dysphagia, as well as occurrence of adverse events including perforation and migration $[19,20]$. Multiple types of self-expandable stents are available. They differ in terms of design, luminal diameter, radial force, flexibility, and degree of shortening after deployment. In Europe, partially or fully covered SEMS are used for the treatment of malignant dysphagia because recurrent dysphagia due to tumor ingrowth has been a major drawback of uncovered SEMSs [21]. In most cases a $100 \%$ technical success rate of stent placement has been reported with an improvement in dysphagia score of at least 2 points (from 3 [liquids only] to 1 [almost all solids]) within $1-2$ days [20]. Most new stent designs have been evaluated in single-arm prospective or retrospective series. SEPS are similar to SEMS with regard to relief of dysphagia in the short term, but adverse events occurred more often with SEPS, especially migration, making SEMS preferable over SEPS for malignant dysphagia [22].

\section{Safety}

The most prevalent adverse events following stent placement are shown in Tablee7 (Appendix e3, available online) and details are also presented in Appendix e3. Analysis of pooled data from RCTs and prospective and retrospective studies showed that major adverse events occur in $18 \%, 21 \%$, and $10 \%$ of patients with PCSEMS, FCSEMS, and SEPS, respectively, while recurrent dysphagia develops in $41 \%, 29 \%$, and $37 \%$ of these patients, respectively [22-39]. Stent insertion-related mortality is $0 \%-2 \%$ $[23,40]$.

\section{For patients with longer life expectancy, ESGE recommends brachytherapy as a valid alternative or in addition to stenting in esophageal cancer patients with malignant dysphagia. Brachytherapy may provide a survival advantage and possibly a better quality of life compared to SEMS placement alone. (Strong recommendation, high quality evidence.)}

Two RCTs have compared SEMS versus brachytherapy. One RCT compared a PCSEMS (Ultraflex) with single-dose intraluminal brachytherapy in 202 patients with incurable esophageal cancer [4]. Compared to SEMS placement, brachytherapy improved dysphagia less rapidly, but after 1 month from treatment, dysphagia score improvement no longer differed significantly between stent placement and brachytherapy. With respect to survival, patients treated by brachytherapy had more days with almost no dysphagia during follow-up than those treated by stent placement. In addition, major complications (i.e., perforation, hemorrhage) occurred more frequently after stent placement than after brachytherapy. There was no difference in recurrent dysphagia and median survival. Quality-of-life (QoL) scores significantly favored brachytherapy, whereas total costs were similar across the two groups. In the other RCT $(n=65)$, insertion of SEMS offered a more immediate relief of dysphagia compared to brachytherapy, but quality of life was better with brachytherapy for patients with longer survival [41]. The main limitations of brachytherapy include limited availability, technical difficulty, and need for dedicated logistics and expertise. Therefore this treatment can only be considered in dedicated centers.
Esophageal stent placement for malignant tracheoesophageal or bronchoesophageal fistula

Esophageal SEMS placement is recommended as the preferred treatment for sealing malignant tracheoesophageal or bronchoesophageal fistula (strong recommendation, low quality evidence).

Application of double stenting (esophagus and airways) can be considered when fistula occlusion is not achieved by esophageal or airway prosthesis alone (strong recommendation, low quality evidence).

Malignant tracheoesophageal or bronchoesophageal fistula develops in $5 \%$ to $15 \%$ of patients with esophageal cancer and in less than $1 \%$ of patients with lung carcinoma $[42,43]$. Because of advances in palliative treatment, the incidence has increased over the last 30 years to above $10 \%$ among all nonresected esophageal cancers [44].

Tracheoesophageal or bronchoesophageal fistulas are usually late developments of advanced cancer of the esophagus, lung, or mediastinum, caused by tumoral invasion or as an adverse event of cancer therapies, in particular chemoradiotherapy [45-47]. Importantly, the condition of such patients has often already significantly deteriorated when they develop a fistula and the remaining life expectancy is short (weeks to months). Rapid relief of disabling symptoms due to the fistula, preferably by minimally invasive treatment, is thus of pivotal importance in order to improve quality of life.

Esophageal stenting is the most widely used approach [48]. Multiple studies using SEMSs for sealing off esophageal - airway fistulas have reported improvement in symptoms and sealing of the fistula in $75 \%-100 \%$ of patients $[2,42,43,49-55]$. Application of double stenting (esophagus and airways) can be considered when fistula occlusion is not achieved by esophageal or airway prosthesis alone [51,56-58]. In the largest prospective series, Shin et al. successfully placed SEMSs in 61 patients with malignant esophageal-airway fistulas, sealing off the fistula in 49 patients $(80 \%)$, while 10 patients $(16 \%)$ required concomitant airway stents [42]. Re-opening of the fistula occurred in 17 patients (35\%); of these, 8 were successfully re-treated with SEMSs, in 2 patients the fistula was closed spontaneously, and 7 patients did not undergo further treatment [42].

Procedure-related complications are reported in $0 \%-27 \%$ of patients with a mortality rate of $0 \%-12 \%[42,43,49,50,52,54]$. In another study that compared quality of life following placement of a SEMS versus gastrostomy or jejunostomy or best supportive care, quality of life improved more with SEMS placement, particularly for symptoms of dyspnea, dysphagia, other eating problems, dry mouth, cough, and hypersalivation [59]. In three large retrospective studies, esophageal stent placement was associated with a significant improvement in survival compared with no sealing of the fistula, a feeding gastrostomy or jejunostomy, or best supportive care $[42,43,50]$.

\section{Stent placement for malignant dysphagia as a bridge to surgery}

ESGE does not recommend SEMS placement as a bridge to surgery or prior to preoperative chemoradiotherapy. It is associated with a high incidence of adverse events, and other satisfactory options such as placement of a feeding tube are preferable. (Strong recommendation, low quality evidence.) 
It is now accepted that neoadjuvant chemotherapy or chemoradiotherapy should be administered to all patients with a resectable esophageal cancer, except for cancers staged 0-IIA [60 - 62]. In a systematic review and meta-analysis of 9 studies ( $\mathrm{n}=180 \mathrm{pa}-$ tients) on esophageal stenting preceding or concomitant with neoadjuvant chemotherapy for esophageal cancer, the procedural success rate was 95\% (95\% confidence interval [95\%CI] 90\%$98 \%$ ) [63]. There was a significant decrease in dysphagia score and a nonsignificant increase in patient weight $(0.6 \mathrm{~kg})$ and serum albumin. However, major adverse events were extremely frequent, including stent migration (incidence 32\%, 95\%CI 26\%$40 \%$ ) and chest discomfort (incidence $51.4 \%$, 95\%CI 21\%-81\%). SEPS were used in 5 of the 9 studies (41\% of patients). The negative impact on oncologic outcome of SEMS placement as bridge to surgery was also confirmed in a large European cohort of 2944 patients [64]. This study showed an in-hospital postoperative mortality and morbidity rate for the SEMS versus control groups of $13.2 \%$ versus $8.6 \%$ and $63.2 \%$ versus $59.2 \%$, respectively. In addition, significant differences in R0 resection (71.0\% vs. $85.5 \%$ ), median time to recurrence (6.5 vs. 9.0 months), and 3-year overall survival ( $25 \%$ vs. $44 \%$ ) were found, to the disadvantage of the SEMS group. The results remained significant after excluding SEMS-related esophageal perforations and after adjusting for confounding factors. Similar unfavorable results have been reported with biodegradable stents as a bridge to surgery [65].

Profound weight loss and malnutrition as a consequence of severe dysphagia and cancer cachexia are cardinal symptoms in esophageal cancer $[66,67]$. To detect nutritional disturbances at an early stage, the European Society for Clinical Nutrition and Metabolism (ESPEN) recommends regular evaluation of nutritional intake, weight change, and body mass index (BMI), at the time of cancer diagnosis and repeated according to the stability of the clinical situation [68]. In patients with digestive cancer, body composition may be quite easily assessed from computed tomography scans [69]. ESPEN recommends nutritional support prior to major surgery in patients with severe nutritional risk (e. g., those with weight loss $>10-15 \%$ within 6 months) as a grade A recommendation [70]. If oral feed intake is inadequate despite counseling and oral nutritional supplements, supplemental enteral nutrition or, if the latter is not sufficient or possible, parenteral nutrition is recommended $[68,71]$. In patients with severe dysphagia, this can be achieved through nasogastric tube placement, percutaneous feeding tube placement, or parenteral nutrition. Percutaneous endoscopic gastrostomy (PEG) or endoscopic jejunostomy is recommended by ESPEN in place of nasogastric tube placement if enteral feeding is scheduled to last more than 2 -3 weeks [72,73]. Furthermore, a Cochrane review of RCTs showed that intervention failure (e.g., feeding interruption, blocking or leakage of the tube, no adherence to treatment) was more frequent with nasogastric tube placement compared with PEG feeding (risk ratio [RR] 0.24, 95\%CI 0.08-0.76) [74]. However, in esophageal cancer patients who are scheduled to undergo a gastric tube reconstruction a PEG placement may be contraindicated, in which case a feeding tube is the preferred treatment. The proportion of patients who refuse placement of a feeding tube in the setting of head and neck cancer patients treated with (chemo)radiation has been found to be very low ( $4 \%$ in an RCT) [75].
Esophageal stents and concomitant palliative treatment with radiotherapy

ESGE does not recommend the concurrent use of radiotherapy if an esophageal stent is present (strong recommendation, low quality evidence).

ESGE suggests that SEMS placement with concurrent single-dose brachytherapy is safe and effective for relief of dysphagia (weak recommendation, low quality evidence).

In contrast to the rapid improvement in dysphagia by stent placement, palliative radiotherapy improves dysphagia after 4 to 6 weeks [76]. Temporary and permanent placement of retrievable metallic stents with concurrent radiotherapy has been suggested as an effective method for increasing survival, immediately improving dysphagia and dietary intake in the period before the effects of radiotherapy become apparent [77-80]. However, a higher risk of life-threatening adverse events has been reported, suggesting that palliative stenting should be delayed until radiotherapy has failed [81-83].

Potential scattering from the metal material in SEMSs may complicate radiation dosimetry. In a simulated clinical protocol measuring the effects of esophageal stents of various materials and designs on radiation effects on tissue adjacent to the stent in the radiation field, a dose enhancement was seen with SEPSs and stainless steel stents, and not with nitinol stents [84]. In another study, dose perturbation by SEMSs was related to the density of the mesh, with a higher density having greater effect, while SEPS and biodegradable stents had minimal-to-no dose effects outside of the radiopaque markers [85].

In contrast to external radiotherapy, the combination of SEMS and single-dose brachytherapy has been reported to be feasible and safe as a palliative treatment in patients with advanced esophageal cancer $[77,86]$. In an RCT that included 53 patients, Guo et al. compared conventional SEMS treatment with SEMS loaded with iodine-125 seeds for brachytherapy; these authors reported a significantly longer dysphagia-free period and longer survival in the irradiation stent group $[25,87]$.

Data on the use of biodegradable stents in patients receiving brachytherapy are limited, but a high rate of major stent-related complications has been described and a normal diet could not be tolerated because of retrosternal pain and vomiting in more than one third of patients [78].

\section{Esophageal stent placement after palliative chemotherapy and radiotherapy}

Data are contradictory with respect to the risk of major adverse events in patients receiving a stent for recurrent malignancy following radiotherapy alone or combined with chemotherapy (RTCT). Some studies show an increased risk while other studies, including a meta-analysis, do not report any relationship between SEMS placement after RTCT and the incidence of life-threatening adverse events or survival; only minor adverse events such as chest pain are associated, suggesting stenting is safe in these patients [18,22,32,88-94]. In detail, the reported rate of life-threatening adverse events ranged from $16 \%$ to $77 \%$ in patients treated with stents after RTCT compared to $0 \%$ to $45 \%$ in patients without previous treatment $[18,22,32,88-91]$. Reported stent-related mortality ranged from $0 \%$ to $54 \%$ in patients with prior RTCT compared to $0 \%$ to $6 \%$ in patients without prior RTCT. 
It has been suggested that the increased risk, if any, of developing life-threatening adverse events, in patients with prior RTCT may be related to the radiation-induced damage on the esophageal wall, potentiated by chemotherapy. However, it is difficult to discern whether such stent-related adverse events are due to stents and radiation effects, the advanced nature of the disease process, or both. Radiotherapy can cause esophagitis, ulcerations, submucosal fibrosis, and vasculitis, with ischemic damage of the esophageal wall causing esophageal perforations and esophageal-respiratory fistulas via local hypoxemia. Although SEMS placement is effective for short-term palliation of malignant dysphagia, stent pressure on a damaged esophageal wall increases the risk of necrosis [89,95-99]. The effect of radiation on the esophageal wall is dose-dependent, with serious damage especially when doses greater than 6 Gy have been administered $[97,99]$. The risks of sudden fatal hemorrhage and formation of a respiratory fistula are relatively high in patients with invasive (T4) cancer $[47,96]$.

\section{ESOPHAGEAL STENTS IN BENIGN DISEASE Refractory benign strictures}

ESGE recommends against the use of SEMSs as first-line therapy for the management of benign esophageal strictures because of the potential for adverse events, the availability of alternative therapies, and costs (strong recommendation, low quality evidence).

Most studies have used expandable stents for treatment of refractory or recurrent esophageal strictures as defined by Kochman: generally when more than 3 to 5 dilations (either mechanical or pneumatic) have been performed without clinical and endoscopic response or when it was impossible to achieve a 14mm lumen over 3 dilation sessions [100]. No studies have compared the clinical efficacy of different initial strategies (i.e., dilation vs. stent placement). Therefore, algorithms are mainly based on the experience of tertiary referral centers [101]. Most experts agree that stent placement should be considered when other treatment options (dilation with or without intralesional triamcinolone acetate injections and/or incisional therapy) have failed, though a clear definition of clinical failure has not been uniformly adopted.

\section{ESGE suggests consideration of temporary placement of self-expandable stents for refractory benign esophageal strictures (weak recommendation moderate quality evidence).}

ESGE does not recommend a specific type of expandable stent (covered metal, plastic, biodegradable) because none has been shown to be superior to any other for this indication (strong recommendation, moderate quality evidence).

A recent systematic review and meta-analysis (10 prospective and 8 retrospective studies; 444 patients) evaluated the clinical outcome of stent placement for refractory benign esophageal stricture (RBES) [102]. FCSEMS were used in 9 studies (227 patients), 8 trials used SEPS (140 patients) and 4 studies used biodegradable stents (77 patients). Overall, the pooled clinical success rate was $40.5 \%$ (95\%CI 31.5\%-49.5\%). Patients treated with SEPS and SEMS did not have significantly different success rates compared with patients treated with biodegradable stents. The overall migration rate was $28.6 \%$ (95\%CI $21.9 \%$ - 37.1\%). Stent removal was successful in $99 \%$ of cases. Finally, the overall adverse event rate was $20.6 \%$ (95\%CI, $15.3 \%-28.1 \%$ ) with no significant difference between the three types of stents. Only one patient died; this was due to massive bleeding.
Factors predicting successful stent treatment

A systematic review demonstrated that the clinical success of stenting in RBES was significantly lower in patients with cervical strictures and for strictures longer than $2 \mathrm{~cm}$ [100]. The latter finding was confirmed by a prospective study showing stricture length as the only factor associated with success, with longer strictures being at higher risk of recurrence (hazard ratio [HR] 1.37, 95\%CI 1.08-1.75) [103]. The previously mentioned review and meta-analysis by Fuccio et al. [102] showed that the etiology of the stricture might influence outcome, with esophageal strictures that had developed after surgical resection or radiation therapy being potentially more responsive to stent treatment. However, no firm conclusion can be drawn because many etiologies of stricture were under-represented and, in many studies, the results were not stratified according to the stricture etiology.

ESGE does not recommend permanent stent placement for refractory benign esophageal stricture; stents should usually be removed at a maximum of 3 months (strong recommendation, weak quality evidence).

No studies have compared different strategies in terms of stenting duration. It is generally accepted that FCSEMSs or SEPSs should remain in place for at least $6-8$ weeks and no more than 12 weeks, to maximize success and to minimize the risk of hyperplastic tissue reaction and stent embedment. Indeed, a large multicenter study that specifically addressed the safety of endoscopic removal of self-expandable stents inserted to treat RBES found no association between indwelling time and the risk of major adverse events [104].

ESGE suggests that FCSEMSs be preferred over PCSEMSs for the treatment of refractory benign esophageal stricture, because of their lack of embedment and ease of removability (weak recommendation, low quality evidence).

The use of partially covered or uncovered SEMS in benign strictures should be avoided because the hyperplastic tissue reaction of the esophageal mucosa to the bare metal mesh often results in recurrent dysphagia. Furthermore, complete embedding of the uncovered metal wires in the esophageal wall may preclude safe stent removal $[105,106]$.

ESGE recommends the stent-in-stent technique to remove PCSEMSs that are embedded in the esophageal wall (strong recommendation, low quality evidence).

In the case of embedded PCSEMSs, temporary placement of a second, fully covered, stent in the first stent ("stent-in-stent" technique) has been shown to facilitate safe removal of the embedded stent, by induction of pressure necrosis of the overgrowing and ingrowing mucosa $[103,107-110]$. Stents used for the stent-instent technique should have a fully covered design and a diameter at least equal to that of the partially covered embedded stent in order to provide sufficient pressure at the site of embedment. In addition, the fully covered stent needs to overlap completely tissue ingrowth inside the lumen of the partially covered stent. The second stent is left in place for 10-14 days, before it is retrieved and removal of the embedded PCSEMS is attempted. The success rate of the stent-in-stent technique is above $90 \%$; in the case of failure, a second FCSEMS should be placed and left in place for 10-14 days before a second attempt to remove the stent is performed [103]. 
Esophageal stent placement in combination with other dilation approaches

ESGE suggests that a combined approach of stent placement with additional techniques (e. g., corticosteroid injection, chemotherapeutic topical application) should not be used in an attempt to improve the long-term benefit of temporary stenting (weak recommendation, very low quality evidence)

Endoscopic incisional therapy has been proposed as either an alternative or additional treatment to endoscopic dilation. Initially proposed for the treatment of recurrent Schatzki rings, it has also been used for the treatment of anastomotic strictures. To our knowledge there have been no studies that have reported using a combined or sequential approach with incisional therapy followed by stent placement.

In order to prevent stricture recurrence, corticosteroid injection into the stricture followed by dilation was proposed more than 10 years ago [111]. Small retrospective studies reporting corticosteroid injection before stent placement do not allow conclusions to be drawn on the additional clinical value for prolonging efficacy following temporary stent placement [112].

Topical application of mitomycin-C has been proposed for refractory corrosive esophageal strictures. Mitomycin- $\mathrm{C}$ is a chemotherapeutic agent that inhibits the proliferation of fibroblasts and collagen synthesis and has been proposed to prevent stricture relapse. There are few available studies, mainly case reports and small series, to support its use, and no studies of this treatment combined with stent placement $[113,114]$.

Treatment options after stent failure for refractory benign esophageal stricture

If refractory benign esophageal stricture has not satisfactorily improved after 2 separate treatments with temporary stenting, ESGE suggests alternative treatment strategies such as self-dilation or surgical treatment (weak recommendation, low quality evidence).

In poor surgical candidates, ESGE recommends self-dilation with rigid dilators (strong recommendation, low quality evidence).

Stent placement for treatment of RBES may be repeated although the majority of studies have demonstrated that additional stent placement does not produce significant incremental benefit $[106,115]$. If sustained stricture resolution is not obtained after temporary stenting on two occasions, the suggested treatment options are self-dilation and surgery. Surgery is advised when possible according to anatomical extent as well as patient condition and willingness to undergo such a complex surgical procedure. The best candidates for self-dilation are those who are selfmotivated, compliant, and poor surgical candidates [116,117]. Based on two retrospective studies, esophageal self-dilation was successful in treating $90 \%$ of patients, with significant improvement in global dysphagia scores and overall quality of life [116, 117].

\section{Benign esophageal leaks, fistulas, and perforations}

ESGE recommends that temporary stent placement can be considered for treatment of leaks, fistulas, and perforations. No specific type of stent can be recommended and the duration of stenting should be individualized. (Strong recommendation, low quality of evidence)

SEMSs have been used for management of perforations and leaks $[118,119]$. Closure of an iatrogenic perforation can also be performed by other endoscopic methods [120]. Table e5 (Appendix e2, available online) shows the results of the published stud- ies on the efficacy and safety of SEMS placement for benign rupture and leakage. In two systematic reviews, the clinical success after placement of temporary stents (FCSEMSs, PCSEMSs, and SEPSs) for benign rupture and anastomotic leaks of the esophagus was similar with different stent types (FSEMS 85\%, PSEMS $86 \%$, SEPS $84 \%[121,122]$. The mean duration of stenting was 7 weeks. Stent migration occurred in $25 \%$, and it occurred more often with SEPS (26\%) and FCSEMS (26\%).

Data on the use of biodegradable stents are limited. In a small study, 4 of 5 patients with an esophageal leak or anastomotic perforation achieved long-term leak sealing after placement of a covered biodegradable stent [123].

The optimal duration of stenting remains unknown. In most studies stent removal was performed 6-8 weeks (range 4-10 weeks) after insertion. Stent-associated esophagorespiratory fistula is a serious adverse event that may occur as a consequence of SEMS placement for benign disease. In one retrospective study of 397 patients, 20 patients developed esophagorespiratory fistulas after a median of 5 months following stent placement [124]. Most fistulas occurred at the proximal edge of the stent and in the setting of prior external radiation therapy; thus the cause may have been ischemic pressure necrosis.

\section{Acute variceal bleeding}

ESGE recommends considering placement of a SEMS for the treatment of esophageal variceal bleeding refractory to medical, endoscopic, and/or radiological therapy, or as initial therapy for patients with massive bleeding (strong recommendation, moderate quality evidence).

- Table e6 (Appendix e2, available online) shows the results of the published studies to date on the applicability, efficacy and safety of covered SEMS for acute esophageal variceal bleeding [125131] Most published studies are observational studies [125131]. Results from these studies are in agreement with a recently published systematic review and meta-analysis showing that treatment with SEMSs is successful in controlling severe or refractory acute variceal bleeding, without the occurrence of severe adverse events and with a 1-month survival of more than $60 \%$; these findings confirmed that this therapy can be used as a bridge to transjugular intrahepatic portosystemic shunt (TIPS) or liver transplantation in a significant proportion of patients [132].

An RCT compared patient outcome after SEMS placement (SXElla Danis stent; $n=13$ ) versus balloon tamponade (SengstakenBlakemore tube; $n=15$ ) in patients with esophageal variceal bleeding refractory to medical and endoscopic treatment [133]. Successful therapy was significantly more frequent in the stent than in the balloon tamponade group (66\% vs. $20 \%$ ) with a significantly higher rate for control of bleeding ( $85 \%$ vs. $47 \%$ ), lower transfusion requirements ( $3 \pm 3.4$ vs. $6 \pm 4.8$ packed red blood cell units), and a lower incidence of serious adverse events (15\% vs. $47 \%$ ), mainly due to differences in aspiration pneumonia (0 vs. 5 ) and esophageal tear (1 patient in the balloon tamponade group). No significant difference in 6-week survival was observed (54\% vs. $40 \%$ ).

Despite the efficacy of stent placement in controlling acute variceal bleeding, a mortality rate of $25 \%$ has been described in these patients, reflecting the seriousness of the underlying condition of the patient in the case of refractory acute variceal bleeding [129]. In published studies SEMSs have remained in place for up to 2 weeks $[125,131,134,135]$. When a dedicated SEMS is used retrieval is done using a specifically designed system (PEX-Ella or extractor for SX-Ella Stent Danis). 
This Guideline, produced by ESGE and endorsed by the European Society for Radiotherapy and Oncology (ESTRO), the European Society of Digestive Oncology (ESDO), and the European Society for Clinical Nutrition and Metabolism (ESPEN), represents a consensus of best practice based on the available evidence at the time of preparation. The Guideline may not apply in all situations and should be interpreted in the light of specific clinical situations and resource availability. Further controlled clinical studies may be needed to clarify aspects of the statements, and revision may be necessary as new data appear. Clinical consideration may justify a course of action at variance to the recommendations. The Guidelines is intended to be an educational device to provide information that may assist endoscopists in providing care to patients. It is not a set of rules and should not be construed as establishing a legal standard of care or as encouraging, advocating, requiring, or discouraging any particular treatment.

Competing interests: T. H. Baron and M. J. Bruno have ongoing lecture/consultancy roles for Cook Medical and Boston Scientific. J-C. Garcia-Pagán has received grants from W. L Gore (20162020), Exalenz (2016-2017) and Novartis (2016-2017). P. D. Siersema received research support from Cook Medical, Ireland (2014-2016). M. C. W. Spaander supported a Boston Scientific esophageal stent trial (2012-2015). M. Conio, A. de Ceglie, J.-M. Dumonceau, A. Escorsell, L. Fuccio, C. Hassan, M. Nordsmark, A. Repici, B. Schumacher, T. Seufferlein, J. Skowronek, A. Van Gossum have no competing interests.

\section{Institutions}

${ }^{1}$ Department of Gastroenterology and Hepatology, Erasmus Medical Center Cancer Institute, Rotterdam, The Netherlands

2 Department of Internal Medicine, Division of Gastroenterology and Hepatology, University of North Carolina, Chapel Hill, North Carolina, USA

${ }^{3}$ Department of Gastroenterology and Hepatology, Radboud University Medical Center, Nijmegen, The Netherlands

${ }^{4}$ Department of Medical and Surgical Sciences, S. Orsola-Malpighi Hospital, University of Bologna, Bologna, Italy

${ }^{5}$ Klinik für Innere Medizin und Gastroenterologie, Elisabeth Krankenhaus

Essen, Essen, Germany

${ }^{6}$ Liver Unit, Hospital Clínic, Barcelona, Spain

${ }^{7}$ Gedyt Endoscopy Center, Buenos Aires, Argentina

${ }^{8}$ Department Gastroenterology and Endoscopy, Ospedale di Sanremo, Sanremo, Italy

${ }^{9}$ Department of Gastroenterology, National Cancer Institute, Bari, Italy

${ }^{10}$ Brachytherapy Department, Greater Poland Cancer Center, Poznan, Poland; Electroradiology Department, Poznan University of Medical Sciences, Poland

${ }^{11}$ Department of Oncology, Aarhus University Hospital, Aarhus, Denmark

${ }^{12}$ Department of Internal Medicine I, Ulm University, Ulm, Germany

${ }^{13}$ Department of Gastroenterology and Hepatology, Hôpital Erasme,

Free University of Brussels, Brussels, Belgium.

${ }^{14}$ Department of Gastroenterology, Nuovo Regina Margherita Hospital, Rome, Italy

${ }^{15}$ Endoscopy Unit, IRCCS Istituto Clinico Humanitas, Rozzano, Milan, Italy

\section{References}

1 Ferlay J, Steliarova-Foucher E, Lortet-Tieulent J et al. Cancer incidence and mortality patterns in Europe: estimates for 40 countries in 2012. Eur J Cancer 2013; 49: 1374 - 1403

2 Van Heel NC, Haringsma J, Spaander MC et al. Esophageal stents for the palliation of malignant dysphagia and fistula recurrence after esophagectomy. Gastrointest Endosc 2010; 72: 249-254

3 van Heel NC, Haringsma J, Spaander MC et al. Esophageal stents for the relief of malignant dysphagia due to extrinsic compression. Endoscopy 2010; 42: 536-540

4 Homs MY, Steyerberg EW, Eijkenboom WM et al. Single-dose brachytherapy versus metal stent placement for the palliation of dysphagia from oesophageal cancer: multicentre randomised trial. Lancet 2004; 364: $1497-1504$

5 Dumonceau JM, Hassan C, Riphaus A et al. European Society of Gastrointestinal Endoscopy (ESGE) Guideline Development Policy. Endoscopy 2012; 44: 626-629
6 Alderson D, Wright PD. Laser recanalization versus endoscopic intubation in the palliation of malignant dysphagia. Br J Surg 1990; 77: $1151-1153$

7 Carter R, Smith JS, Anderson JR. Laser recanalization versus endoscopic intubation in the palliation of malignant dysphagia: a randomized prospective study. Br J Surg 1992; 79: 1167-1170

8 Fuchs $\mathrm{KH}$, Freys SM, Schaube $\mathrm{H}$ et al. Randomized comparison of endoscopic palliation of malignant esophageal stenoses. Surg Endosc 1991; 5: $63-67$

9 Adam A, Ellul J, Watkinson AF et al. Palliation of inoperable esophageal carcinoma: a prospective randomized trial of laser therapy and stent placement. Radiology 1997; 202: 344-348

10 Dallal HJ, Smith GD, Grieve DC et al. A randomized trial of thermal ablative therapy versus expandable metal stents in the palliative treatment of patients with esophageal carcinoma. Gastrointest Endosc 2001; 54: $549-557$

11 Aoki T, Osaka Y, Takagi $Y$ et al. Comparative study of self-expandable metallic stent and bypass surgery for inoperable esophageal cancer. Dis Esophagus 2001; 14: 208-211

12 Knyrim K, Wagner HJ, Bethge $N$ et al. A controlled trial of an expansile metal stent for palliation of esophageal obstruction due to inoperable cancer. New Engl J Med 1993; 329: $1302-1307$

13 Roseveare $C D$, Patel $P$, Simmonds $N$ et al. Metal stents improve dysphagia, nutrition and survival in malignant oesophageal stenosis: a randomized controlled trial comparing modified Gianturco Z-stents with plastic Atkinson tubes. Eur J Gastroenterol Hepatol 1998; 10: 653-657

14 De Palma GD, di Matteo E, Romano $G$ et al. Plastic prosthesis versus expandable metal stents for palliation of inoperable esophageal thoracic carcinoma: a controlled prospective study. Gastrointest Endosc 1996; 43: $478-482$

15 O'Donnell CA, Fullarton GM, Watt E et al. Randomized clinical trial comparing self-expanding metallic stents with plastic endoprostheses in the palliation of oesophageal cancer. Br J Surg 2002; 89: 985-992

16 Sanyika C, Corr P, Haffejee A. Palliative treatment of oesophageal carcinoma - efficacy of plastic versus self-expandable stents. S Afr Med J 1999; 89: 640-643

17 Shenfine J, McNamee P, Steen $N$ et al. A pragmatic randomised controlled trial of the cost-effectiveness of palliative therapies for patients with inoperable oesophageal cancer. Health Technol Assess 2005; 9: iii, $1-121$

18 Siersema PD, Hop WC, Dees J et al. Coated self-expanding metal stents versus latex prostheses for esophagogastric cancer with special reference to prior radiation and chemotherapy: a controlled, prospective study. Gastrointest Endosc 1998; 47: 113-120

19 Sreedharan A, Harris $K$, Crellin A et al. Interventions for dysphagia in oesophageal cancer. Cochrane Database Syst Rev 2009; 4: CD005048

20 Dai Y, Li C, Xie Y et al. Interventions for dysphagia in oesophageal cancer. Cochrane Database Syst Rev 2014; 10: CD005048

21 Vakil N, Morris AI, Marcon N et al. A prospective, randomized, controlled trial of covered expandable metal stents in the palliation of malignant esophageal obstruction at the gastroesophageal junction. Am J Gastroenterol 2001; 96: 1791 -1796

22 Conio M, Repici A, Battaglia G et al. A randomized prospective comparison of self-expandable plastic stents and partially covered self-expandable metal stents in the palliation of malignant esophageal dysphagia. Am J Gastroenterol 2007; 102: 2667 -2677

23 Parthipun A, Diamantopoulos A, Shaw A et al. Self-expanding metal stents in palliative malignant oesophageal dysplasia. Ann Palliat Med 2014; 3: $92-103$

24 van Heel NC, Haringsma J, Boot $\mathrm{H}$ et al. Comparison of 2 expandable stents for malignant esophageal disease: a randomized controlled trial. Gastrointest Endosc 2012; 76: $52-58$

$25 \mathrm{Zhu} H \mathrm{H}$, Guo JH, Mao AW et al. Conventional stents versus stents loaded with (125)iodine seeds for the treatment of unresectable oesophageal cancer: a multicentre, randomised phase 3 trial. Lancet Oncol 2014; 15: $612-619$

26 Blomberg J, Wenger U, Lagergren JE et al. Antireflux stent versus conventional stent in the palliation of distal esophageal cancer. A randomized, multicenter clinical trial. Scand J Gastroenterol 2010; 45: 208 216

27 Shenfine J, McNamee P, Steen $N$ et al. A randomized controlled clinical trial of palliative therapies for patients with inoperable esophageal cancer. Am J Gastroenterol 2009; 104: 1674-1685 
28 Kim ES, Jeon SW, Park SY et al. Comparison of double-layered and covered Niti-S stents for palliation of malignant dysphagia. J Gastroenterol Hepatol 2009; 24: 114-119

29 Sabharwal T, Hamady MS, Chui S et al. A randomised prospective comparison of the Flamingo Wallstent and Ultraflex stent for palliation of dysphagia associated with lower third oesophageal carcinoma. Gut 2003; 52: 922 - 926

30 Verschuur EM, Repici A, Kuipers EJ et al. New design esophageal stents for the palliation of dysphagia from esophageal or gastric cardia cancer: a randomized trial. Am J Gastroenterol 2008; 103: $304-312$

31 Siersema PD, Hop WC, van Blankenstein $M$ et al. A comparison of 3 types of covered metal stents for the palliation of patients with dysphagia caused by esophagogastric carcinoma: a prospective, randomized study. Gastrointest Endosc 2001; 54: 145-153

32 Sgourakis G, Gockel I, Radtke A et al. The use of self-expanding stents in esophageal and gastroesophageal junction cancer palliation: a meta-analysis and meta-regression analysis of outcomes. Dig Dis Sci 2010; 55: $3018-3030$

33 Yakoub D, Fahmy R, Athanasiou T et al. Evidence-based choice of esophageal stent for the palliative management of malignant dysphagia. World J Surg 2008; 32: 1996 - 2009

34 Power C, Byrne PJ, Lim K et al. Superiority of anti-reflux stent compared with conventional stents in the palliative management of patients with cancer of the lower esophagus and esophago-gastric junction: results of a randomized clinical trial. Dis Esophagus 2007; 20: 466-470

35 Wenger $U$, Johnsson E, Arnelo $U$ et al. An antireflux stent versus conventional stents for palliation of distal esophageal or cardia cancer: a randomized clinical study. Surg Endosc 2006; 20: 1675-1680

36 Homs MY, Wahab PJ, Kuipers EJ et al. Esophageal stents with antireflux valve for tumors of the distal esophagus and gastric cardia: a randomized trial. Gastrointest Endosc 2004; 60: 695-702

37 Sabharwal T, Gulati MS, Fotiadis $N$ et al. Randomised comparison of the FerX Ella antireflux stent and the ultraflex stent: proton pump inhibitor combination for prevention of post-stent reflux in patients with esophageal carcinoma involving the esophago-gastric junction. J Gastroenterol Hepatol 2008; 23: $723-728$

38 Laasch HU, Marriott A, Wilbraham L et al. Effectiveness of open versus antireflux stents for palliation of distal esophageal carcinoma and prevention of symptomatic gastroesophageal reflux. Radiology 2002; 225: $359-365$

39 Saranovic D, Djuric-Stefanovic A, Ivanovic A et al. Fluoroscopically guided insertion of self-expandable metal esophageal stents for palliative treatment of patients with malignant stenosis of esophagus and cardia: comparison of uncovered and covered stent types. Dis Esophagus 2005; 18: $230-238$

40 Katsanos K, Sabharwal T, Koletsis E et al. Direct erosion and prolapse of esophageal stents into the tracheobronchial tree leading to life-threatening airway compromise. J Vasc Intervent Radiol 2009; 20: 1491 1495

41 Bergquist $H$, Wenger $U$, Johnsson $E$ et al. Stent insertion or endoluminal brachytherapy as palliation of patients with advanced cancer of the esophagus and gastroesophageal junction. Results of a randomized, controlled clinical trial. Dis Esophagus 2005; 18: 131 - 139

42 Shin JH, Song HY, Ko GY et al. Esophagorespiratory fistula: long-term results of palliative treatment with covered expandable metallic stents in 61 patients. Radiology 2004; 232: $252-259$

43 Balazs A, Kupcsulik PK, Galambos Z. Esophagorespiratory fistulas of tumorous origin. Non-operative management of 264 cases in a 20-year period. Eur J Cardiothorac Surg 2008; 34: 1103-1107

44 Hürtgen $M$, Herber SC. Treatment of malignant tracheoesophageal fistula. Thorac Surg Clin 2014; 24: 117-127

45 Gore E, Currey A, Choong $N$. Tracheoesophageal fistula associated with bevacizumab 21 months after completion of radiation therapy. J Thorac Oncol 2009; 4: 1590-1591

46 Spigel DR, Hainsworth JD, Yardley DA et al. Tracheoesophageal fistula formation in patients with lung cancer treated with chemoradiation and bevacizumab. J Clin Oncol 2010; 28: 43-48

47 Didden P, Spaander MC, Kuipers EJ et al. Safety of stent placement in recurrent or persistent esophageal cancer after definitive chemoradiotherapy: a case series. Gastrointest Endosc 2012; 76: 426-430

48 Didden P, Spaander MC, Bruno MJ et al. Esophageal stents in malignant and benign disorders. Curr Gastroenterol Rep 2013; 15: 319

49 Sarper $A, O z N$, Cihangir $C$ et al. The efficacy of self-expanding metal stents for palliation of malignant esophageal strictures and fistulas. Eur J Cardiothorac Surg 2003; 23: $794-798$
50 Chen YH, Li SH, Chiu YC et al. Comparative study of esophageal stent and feeding gastrostomy/jejunostomy for tracheoesophageal fistula caused by esophageal squamous cell carcinoma. PloS One 2012; 7 : e42766 DOI 10.1371/journal.pone.0042766

51 Rodriguez AN, Diaz-Jimenez JP. Malignant respiratory-digestive fistulas. Curr Opin Pulm Med 2010; 16: 329-333

52 Dumonceau JM, Cremer M, Lalmand B et al. Esophageal fistula sealing. choice of stent, practical management, and cost. Gastrointest Endosc 1999; 49: $70-78$

53 May A, Ell C. Palliative treatment of malignant esophagorespiratory fistulas with Gianturco-Z stents. A prospective clinical trial and review of the literature on covered metal stents. Am J Gastroenterol 1998; 93: $532-535$

54 Raijman I. Endoscopic management of esophagorespiratory fistulas: expanding our options with expandable stents. Am J Gastroenterol 1998; 93: 496 - 499

55 Sharma P, Kozarek R. Practice Parameters Committee of American College of Gastroenterology. Role of esophageal stents in benign and malignant diseases. Am J Gastroenterol 2010; 105: 258 - 273; quiz 74

56 Freitag L, Tekolf E, Steveling $H$ et al. Management of malignant esophagotracheal fistulas with airway stenting and double stenting. Chest 1996; 110: 1155 - 1160

57 Colt HG, Meric B, Dumon JF. Double stents for carcinoma of the esophagus invading the tracheo-bronchial tree. Gastrointest Endosc 1992; 38: $485-489$

58 Albes JM, Schafers HJ, Gebel M et al. Tracheal stenting for malignant tracheoesophageal fistula. Ann Thorac Surg 1994; 57: 1263-1266

$59 \mathrm{Hu}$ Y, Zhao YF, Chen LQ et al. Comparative study of different treatments for malignant tracheoesophageal/bronchoesophageal fistulae. Dis Esophagus 2009; 22: 526 - 531

60 Sjoquist KM, Burmeister BH, Smithers BM et al. Survival after neoadjuvant chemotherapy or chemoradiotherapy for resectable oesophageal carcinoma: an updated meta-analysis. Lancet Oncol 2011; 12: 681 692

61 Walsh TN. Oesophageal cancer: who needs neoadjuvant therapy? Lancet Oncol 2011; 12: 615-616

62 Sobin LH, Compton CC. TNM seventh edition: what's new, what's changed: communication from the International Union Against Cancer and the American Joint Committee on Cancer. Cancer 2010; 116: 5336 5339

63 Nagaraja V, Cox MR, Eslick GD. Safety and efficacy of esophageal stents preceding or during neoadjuvant chemotherapy for esophageal cancer: a systematic review and meta-analysis. J Gastrointest Oncol 2014; 5: $119-126$

64 Mariette C, Gronnier C, Duhamel A et al. Self-expanding covered metallic stent as a bridge to surgery in esophageal cancer: impact on oncologic outcomes. J Am Coll Surg 2015; 220: 287-296

65 van den Berg MW, Walter D, de Vries EM et al. Biodegradable stent placement before neoadjuvant chemoradiotherapy as a bridge to surgery in patients with locally advanced esophageal cancer. Gastrointest Endosc 2014; 80: 908 -913

66 Anandavadivelan $P$, Lagergren $P$. Cachexia in patients with oesophageal cancer. Nat Rev Clin Oncol 2016; 13: 185-198 DOI 10.1038/nrclinonc. 2015.200

67 Hébuterne X, Lemarie E, Michallet $M$ et al. Prevalence of malnutrition and current use of nutrition support in patients with cancer. JPEN J Parenter Enteral Nutr 2014; 38: 196 - 204

68 Arends J. ESPEN guidelines for nutrition in cancer patients. Clin Nutr 2016: submitted

69 Kazemi-Bajestani SM, Mazurak VC, Baracos V. Computed tomographydefined muscle and fat wasting are associated with cancer clinical outcomes. Semin Cell Dev Biol 2016; 54: 2-10 DOI 10.1016/j. semcdb.2015.09.001

70 Weimann A, Braga M, Harsanyi L et al. ESPEN guidelines on enteral nutrition: surgery including organ transplantation. Clin Nutr 2006; 25 : $224-244$

71 Senesse P, Assenat E, Schneider S et al. Nutritional support during oncologic treatment of patients with gastrointestinal cancer: who could benefit? Cancer Treat Rev 2008; 34: 568 - 575

72 Loser C, Aschl G, Hébuterne X et al. ESPEN guidelines on artificial enteral nutrition - percutaneous endoscopic gastrostomy (PEG). Clin Nutr 2005; 24: $848-861$

73 Toussaint E, Van Gossum A, Ballarin A et al. Enteral access in adults. Clin Nutr 2015; 34: $350-358$ 
74 Gomes CAJr, Lustosa SA, Matos D et al. Percutaneous endoscopic gastrostomy versus nasogastric tube feeding for adults with swallowing disturbances. Cochrane Database Syst Rev 2012; 3: CD008096

75 Corry J, Poon W, McPhee $N$ et al. Randomized study of percutaneous endoscopic gastrostomy versus nasogastric tubes for enteral feeding in head and neck cancer patients treated with (chemo)radiation. J Med Imaging Radiat Oncol 2008; 52: 503 - 510

76 Shin JH, Song HY, Kim JH et al. Comparison of temporary and permanent stent placement with concurrent radiation therapy in patients with esophageal carcinoma. J Vasc Intervent Radiol 2005; 16: 67 - 74

77 Bergquist H, Johnsson E, Nyman J et al. Combined stent insertion and single high-dose brachytherapy in patients with advanced esophageal cancer - results of a prospective safety study. Dis Esophagus 2012; 25: $410-415$

78 Hirdes MM, van Hooft JE, Wijrdeman HK et al. Combination of biodegradable stent placement and single-dose brachytherapy is associated with an unacceptably high complication rate in the treatment of dysphagia from esophageal cancer. Gastrointest Endosc 2012; 76: 267 274

79 Park JH, Song HY, Park JY et al. Temporary stent placement with concurrent chemoradiation therapy in patients with unresectable oesophageal carcinoma: is there an optimal time for stent removal? Eur Radiol 2013; 23: 1940 - 1945

80 Song HY, Lee DH, Seo TS et al. Retrievable covered nitinol stents: experiences in 108 patients with malignant esophageal strictures. J Vasc Intervent Radiol 2002; 13: $285-293$

81 Nishimura Y, Nagata K, Katano $S$ et al. Severe complications in advanced esophageal cancer treated with radiotherapy after intubation of esophageal stents: a questionnaire survey of the Japanese Society for Esophageal Diseases. Int J Radiat Oncol Biol Phys 2003; 56: 1327 1332

82 Zhong J, Wu Y, Xu Z et al. Treatment of medium and late stage esophageal carcinoma with combined endoscopic metal stenting and radiotherapy. Chin Med J (Engl) 2003; 116: 24-28

83 Javed A, Pal S, Dash NR et al. Palliative stenting with or without radiotherapy for inoperable esophageal carcinoma: a randomized trial. Gastrointest Cancer 2012; 43: 63-69

84 Chen YK, Schefter TE, Newman F. Esophageal cancer patients undergoing external beam radiation after placement of self-expandable metal stents: is there a risk of radiation dose enhancement? Gastrointest Endosc 2011; 73: 1109-1114

85 Abu Dayyeh BB, Vandamme IJ, Miller RC et al. Esophageal self-expandable stent material and mesh grid density are the major determining factors of external beam radiation dose perturbation: results from a phantom model. Endoscopy 2013; 45: $42-47$

86 Amdal $C D$, Jacobsen $A B$, Sandstad $B$ et al. Palliative brachytherapy with or without primary stent placement in patients with oesophageal cancer, a randomised phase III trial. Radiother Oncol 2013; 107: 428-433

87 Guo JH, Teng GJ, Zhu GY et al. Self-expandable esophageal stent loaded with 125 I seeds: initial experience in patients with advanced esophageal cancer. Radiology 2008; 247: 574 - 581

88 Homs MY, Hansen BE, van Blankenstein $M$ et al. Prior radiation and/or chemotherapy has no effect on the outcome of metal stent placement for oesophagogastric carcinoma. Eur J Gastroenterol Hepatol 2004; 16: $163-170$

89 Iraha Y, Murayama S, Toita T et al. Self-expandable metallic stent placement for patients with inoperable esophageal carcinoma: investigation of the influence of prior radiotherapy and chemotherapy. Radiat Med 2006; 24: 247-252

90 Rueth NM, Shaw D, D'Cunha J et al. Esophageal stenting and radiotherapy: a multimodal approach for the palliation of symptomatic malignant dysphagia. Ann Surg Oncol 2012; 19: 4223-4228

91 Bethge $N$, Sommer $A$, von Kleist $D$ et al. A prospective trial of self-expanding metal stents in the palliation of malignant esophageal obstruction after failure of primary curative therapy. Gastrointest Endosc 1996; 44: $283-286$

92 Siddiqui AA, Glynn C, Loren D et al. Self-expanding plastic esophageal stents versus jejunostomy tubes for the maintenance of nutrition during neoadjuvant chemoradiation therapy in patients with esophageal cancer: a retrospective study. Dis Esophagus 2009; 22: 216-222

93 Bower $M$, Jones $W$, Vessels $B$ et al. Nutritional support with endoluminal stenting during neoadjuvant therapy for esophageal malignancy. Ann Surg Oncol 2009; 16: 3161 - 3168

94 Adler DG, Fang J, Wong $R$ et al. Placement of Polyflex stents in patients with locally advanced esophageal cancer is safe and improves dyspha- gia during neoadjuvant therapy. Gastrointest Endosc 2009; 70: 614 619

95 Muto M, Ohtsu A, Miyata Y et al. Self-expandable metallic stents for patients with recurrent esophageal carcinoma after failure of primary chemoradiotherapy. Jpn J Clin Oncol 2001; 31: 270 - 274

96 Sumiyoshi T, Gotoda T, Muro K et al. Morbidity and mortality after selfexpandable metallic stent placement in patients with progressive or recurrent esophageal cancer after chemoradiotherapy. Gastrointest Endosc 2003; 57: $882-885$

97 Lecleire S, Di Fiore F, Ben-Soussan E et al. Prior chemoradiotherapy is associated with a higher life-threatening complication rate after palliative insertion of metal stents in patients with oesophageal cancer. Aliment Pharmacol Ther 2006; 23: 1693-1702

98 Park JY, Shin JH, Song HY et al. Airway complications after covered stent placement for malignant esophageal stricture: special reference to radiation therapy. AJR Am J Roentgenol 2012; 198: 453-9

99 Qiu G, Tao Y, Du X et al. The impact of prior radiotherapy on fatal complications after self-expandable metallic stents (SEMS) for malignant dysphagia due to esophageal carcinoma. Dis Esophagus 2013; 26 : $175-181$

100 Repici A, Hassan C, Sharma P et al. Systematic review: the role of selfexpanding plastic stents for benign oesophageal strictures. Aliment Pharmacol Ther 2010; 31: 1268-1275

101 Thomas T, Abrams KR, Subramanian V et al. Esophageal stents for benign refractory strictures: a meta-analysis. Endoscopy 2011; 43: $386-393$

102 Fuccio L, Hassan C, Frazzoni L et al. Clinical outcomes following stent placement in refractory benign esophageal stricture: a systematic review and meta-analysis. Endoscopy 2016; 48: 141 -148

103 Canena JM, Liberato MJ, Rio-Tinto RA et al. A comparison of the temporary placement of 3 different self-expanding stents for the treatment of refractory benign esophageal strictures: a prospective multicentre study. BMC Gastroenterol 2012; 12: 70

104 van Halsema EE, Wong Kee Song LM et al. Safety of endoscopic removal of self-expandable stents after treatment of benign esophageal diseases. Gastrointest Endosc 2013; 77: 18-28

105 Ackroyd R, Watson DI, Devitt PG et al. Expandable metallic stents should not be used in the treatment of benign esophageal strictures J Gastroenterol Hepatol 2001; 16: 484-487

106 Hirdes MM, Siersema PD, van Boeckel PG et al. Single and sequential biodegradable stent placement for refractory benign esophageal strictures: a prospective follow-up study. Endoscopy 2012; 44 $649-654$

107 van Boeckel PG, Vleggaar FP, Siersema PD. A comparison of temporary self-expanding plastic and biodegradable stents for refractory benign esophageal strictures. Clin Gastroenterol Hepatol 2011; 9: 653-659

108 Dumonceau JM, Deviere J. Treatment of Boerhaave's syndrome using the ultraflex self-expandable stent. Gastrointest Endosc 2000; 51: $773-774$

109 Evrard S, Le Moine O, Lazaraki G et al. Self-expanding plastic stents for benign esophageal lesions. Gastrointest Endosc 2004; 60: 894-900

110 Swinnen J, Eisendrath P, Rigaux J et al. Self-expandable metal stents for the treatment of benign upper GI leaks and perforations. Gastrointest Endosc 2011; 73: 890-899

111 Ramage JIJr, Rumalla A, Baron TH et al. A prospective, randomized, double-blind, placebo-controlled trial of endoscopic steroid injection therapy for recalcitrant esophageal peptic strictures. Am J Gastroenterol 2005; 100: 2419-2425

112 Wilson JL, Louie BE, Farivar AS et al. Fully covered self-expanding metal stents are effective for benign esophagogastric disruptions and strictures. J Gastrointest Surg 2013; 17: 2045-2050

113 Spier BJ, Sawma VA, Gopal DV et al. Intralesional mitomycin C: successful treatment for benign recalcitrant esophageal stricture. Gastrointest Endosc 2009; 69: 152-153; discussion 3

114 Nagaich N, Nijhawan S, Katiyar P et al. Mitomycin-C: 'a ray of hope' in refractory corrosive esophageal strictures. Dis Esophagus 2014; 27: $203-205$

115 Repici A, Small AJ, Mendelson A et al. Natural history and management of refractory benign esophageal strictures. Gastrointest Endosc 2016: DOI 10.1016/j.gie.2016.01.053

116 Dzeletovic I, Fleischer DE. Self-dilation for resistant, benign esophageal strictures. Am J Gastroenterol 2010; 105: 2142 - 2143

117 Dzeletovic I, Fleischer DE, Crowell MD et al. Self dilation as a treatment for resistant benign esophageal strictures: outcome, technique, and quality of life assessment. Dig Dis Sci 2011; 56: 435-440 
118 van Heel NC, Haringsma J, Spaander MC et al. Short-term esophageal stenting in the management of benign perforations. Am J Gastroenterol 2010; 105: 1515-1520

119 Eloubeidi MA, Talreja JP, Lopes TL et al. Success and complications associated with placement of fully covered removable self-expandable metal stents for benign esophageal diseases (with videos). Gastrointest Endosc 2011; 73: 673-681

120 Paspatis GA, Dumonceau JM, Barthet $M$ et al. Diagnosis and management of iatrogenic endoscopic perforations: European Society of Gastrointestinal Endoscopy (ESGE) Position Statement. Endoscopy 2014; 46: $693-711$

121 van Boeckel PG, Sijbring A, Vleggaar FP et al. Systematic review: temporary stent placement for benign rupture or anastomotic leak of the oesophagus. Aliment Pharmacol Ther 2011; 33: 1292 - 1301

122 Dasari BV, Neely D, Kennedy A et al. The role of esophageal stents in the management of esophageal anastomotic leaks and benign esophageal perforations. Ann Surg 2014; 259: 852 - 860

123 Cerna M, Kocher M, Valek V et al. Covered biodegradable stent: new therapeutic option for the management of esophageal perforation or anastomotic leak. Cardiovasc Intervent Radiol 2011; 34: 1267-1271

124 Bick BL, Song LM, Buttar NS et al. Stent-associated esophagorespiratory fistulas: incidence and risk factors. Gastrointest Endosc 2013; 77: $181-189$

125 Wright G, Lewis $H$, Hogan B et al. A self-expanding metal stent for complicated variceal hemorrhage: experience at a single center. Gastrointest Endosc 2010; 71: 71 - 78

126 Dechêne A, El Fouly AH, Bechmann LP et al. Acute management of refractory variceal bleeding in liver cirrhosis by self-expanding metal stents. Digestion 2012; 85: 185 - 191

127 Holster IL, Kuipers EJ, van Buuren HR et al. Self-expandable metal stents as definitive treatment for esophageal variceal bleeding. Endoscopy 2013; 45: 485-488

128 Fierz FC, Kistler W, Stenz V et al. Treatment of esophageal variceal hemorrhage with self-expanding metal stents as a rescue maneuver in a swiss multicentric cohort. Case Rep Gastroenterol 2013; 7: 97-105

129 Zakaria MS, Hamza IM, Mohey MA et al. The first Egyptian experience using new self-expandable metal stents in acute esophageal variceal bleeding: pilot study. Saudi J Gastroenterol 2013; 19: 177-181

130 Hubmann R, Bodlaj G, Czompo M et al. The use of self-expanding metal stents to treat acute esophageal variceal bleeding. Endoscopy 2006; 38: $896-901$
131 Zehetner J, Shamiyeh A, Wayand W et al. Results of a new method to stop acute bleeding from esophageal varices: implantation of a selfexpanding stent. Surg Endosc 2008; 22: 2149-2152

132 Marot A, Trepo E, Doerig $C$ et al. Systematic review with meta-analysis: self-expanding metal stents in patients with cirrhosis and severe or refractory oesophageal variceal bleeding. Aliment Pharmacol Ther 2015; 42: $1250-1260$

133 Escorsell A, Pavel O, Cardenas A et al. Esophageal balloon tamponade versus esophageal stent in controlling acute refractory variceal bleeding: A multicenter randomized controlled trial. Hepatology 2015; 53: 1957-1967

134 Escorsell A, Bosch J. Self-expandable metal stents in the treatment of acute esophageal variceal bleeding. Gastroenterol Res Pract 2011: DOI 10.1155/2011/910986

135 van Hooft JE, van Berge Henegouwen MI, Rauws EA et al. Endoscopic treatment of benign anastomotic esophagogastric strictures with a biodegradable stent. Gastrointest Endosc 2011; 73: 1043-1047

136 Hirdes MM, Vleggaar FP, Siersema PD. Stent placement for esophageal strictures: an update. Expert Rev Medical Devices 2011; 8: 733 - 755

137 Shim CS, Cho YD, Moon JH et al. Fixation of a modified covered esophageal stent: its clinical usefulness for preventing stent migration. Endoscopy 2001; 33: 843-848

138 da Costa Martins B, Medrado BF, de Lima MS et al. Esophageal metallic stent fixation with dental floss: a simple method to prevent migration. Endoscopy 2013; 45: E342 DOI 10.1055/s-0033-1344129

139 Kato H, Fukuchi M, Miyazaki T et al. Endoscopic clips prevent self-expandable metallic stent migration. Hepatogastroenterology 2007; 54: $1388-1390$

140 Vanbiervliet G, Filippi J, Karimdjee BS et al. The role of clips in preventing migration of fully covered metallic esophageal stents: a pilot comparative study. Surg Endosc 2012; 26: 53-59

141 Kantsevoy SV, Bitner M. Esophageal stent fixation with endoscopic suturing device (with video). Gastrointest Endosc 2012; 76: 1251 1255

142 Holm AN, de la Mora Levy JG, Gostout CJ et al. Self-expanding plastic stents in treatment of benign esophageal conditions. Gastrointest Endosc 2008; 67: 20-25

143 D'Cunha J, Rueth NM, Groth SS et al. Esophageal stents for anastomotic leaks and perforations. J Thorac Cardiovasc Surg 2011; 142: 39-46.e1

Appendix e1, e2, e3

online content viewable at:

http://dx.doi.org/10.1055/s-0042-114210 